\title{
Ecdysteroids in the oceanic copepod Calanus pacificus: variation during molt cycle and change associated with diapause
}

\author{
Catherine Lynn Johnson ${ }^{1,2, *}$ \\ ${ }^{1}$ Integrative Oceanography Division, Scripps Institution of Oceanography, La Jolla, California 92093-0218, USA \\ ${ }^{2}$ Present address: Department of Engineering Mathematics, Dalhousie University, PO Box 1000, Halifax, \\ Nova Scotia B3J 2X4, Canada
}

\begin{abstract}
Development through the molt cycle in arthropods is characterized both by changes in exoskeleton morphology and by cyclical changes in ecdysteroids, i.e. molting hormones. This study describes for Calanus pacificus ecdysteroid variation during the molt cycle in the fifth copepodid (CV) stage and compares ecdysteroid content of diapausing and active field-collected CVs. In $C$. pacificus CVs, the pattern of ecdysteroid variation relative to the molt cycle phase is similar to that found in decapod crustacean larvae. Ecdysteroid levels are lowest in the postmolt, the first phase after molting, and then increase to a peak during early premolt. Ecdysteroid levels measured in fieldcollected diapausing C. pacificus CVs were lower than those in active CVs, as expected based on the predominance of the postmolt phase among diapausing CVs. Ecdysteroid analysis provides a faster, less labor-intensive alternative to jaw-phase analysis for identifying the molt phase of field-collected copepodids, and can provide valuable insights into their life-history status. Measurement of copepod hormonal status in situ may provide a direct means of determining the proximate cues for diapause induction and termination in oceanic copepods.
\end{abstract}

KEY WORDS: Calanus pacificus · California Current $\cdot$ Copepod $\cdot$ Diapause $\cdot$ Dormancy $\cdot$ Ecdysteroids · Molting hormone $\cdot$ Zooplankton

Resale or republication not permitted without written consent of the publisher

\section{INTRODUCTION}

Developmental rates of oceanic copepods in nature may at times be greatly reduced, for example during diapause or starvation. The morphology of jaw (mandibular gnathobase) development, an indicator of progression through the molt cycle, has been used to identify population-level shifts toward earlier molt phases associated with such periods of developmental delay (Miller \& Terazaki 1989, Miller et al. 1991, Crain \& Miller 2001). 'Molt phase' is used here to denote substages within a developmental stage. Shifts in moltphase distribution during these events are expected to be accompanied by changes in average ecdysteroid (molting hormone) level, if ecdysteroids vary through the molt cycle of copepods as in many other arthropods (Steel \& Vafopolou 1989). Ecdysteroid analysis may, therefore, identify copepod molt status at the popula- tion level, thus facilitating identification of starvation, diapause, or preparation for diapause in field-collected copepods. Because of the difficulty of inducing diapause under controlled conditions, identification of preparation for diapause in field-collected copepods may be essential for determining the environmental cues that induce diapause in Calanus pacificus and other dominant oceanic copepods.

Ecdysteroid control of the molt cycle is well characterized in insects and decapod crustaceans (Nijhout 1994, Charmantier et al. 1997). Ecdysteroids are a family of steroid hormones that act by regulating gene expression (Spindler et al. 2001). The regulatory effects of ecdysteroids are concentration-dependent, and ecdysteroid level typically is low after molting, increases during preparation for ecdysis, and decreases just prior to ecdysis in both decapods and non-metamorphic molts of insects (schematic diagram: Fig. 1) (see also 
Steel \& Vafopolou 1989). In decapods, the period of low ecdysteroid after molting corresponds to the postmoltthrough-intermolt phases of exoskeleton development (Fig. 1: A-C, originally defined by Drach 1939). Ecdysteroid level peaks in the premolt phase of the molt cycle, during which the old exoskeleton is degraded and a new exoskeleton is secreted. The peak is most commonly in the $\mathrm{D}_{2}$ or $\mathrm{D}_{3}$ sub-phases of premolt; however, it may be earlier (in the $\mathrm{D}_{1}$ sub-phase) in decapod larvae (Skinner 1985, Spindler \& Anger 1986, Anger \& Spindler 1987). This characteristic pattern is found in both hemolymph ecdysteroid titers of adult, juvenile, and larval decapods and whole-body ecdysteroid content of decapod larvae (Chang \& Bruce 1981, Spindler \& Anger 1986, Chang et al. 2001). Additional, higher frequency variability may be superimposed on the characteristic pattern of ecdysteroid variation due to the complex interactions among ecdysteroid production, inactivation, excretion, and uptake (Steel \& Vafopolou 1989, Snyder \& Chang 1991a, Spindler et al. 2001). In decapods, ecdysone is the primary form of ecdysteroid secreted by the Y-organ; 25-deoxyecdysone and 3-dehydroecdysone are also secreted. Ecdysone is hydroxylated to 20-hydroxyecdysone, the active form of ecdysteroid, in decapod tissues (Chang 1995, Charmantier et al. 1997). Ecdysteroids have not previously been measured in copepods; however, ecdysteroid activity has been inferred from bioassays on the copepod Euchaeta norvegica (Carlisle 1965).

Because suppression of molting is characteristic of diapause, this study compares ecdysteroid levels in diapausing and active Calanus pacificus. The faculta-

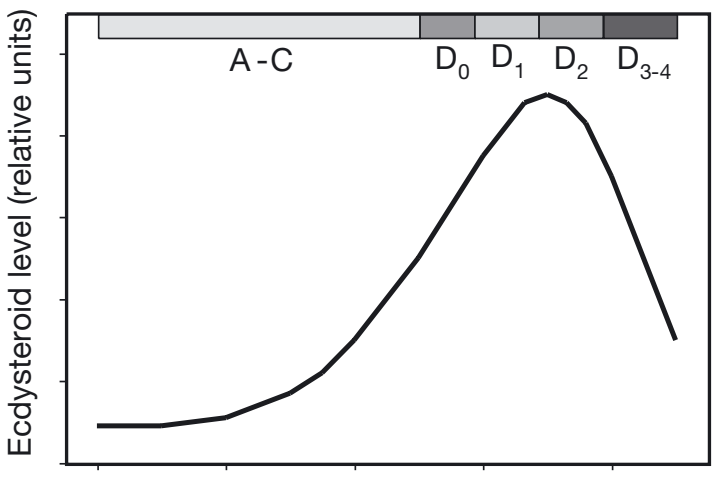

Time since onset of developmental stage

Fig. 1. Schematic representation of ecdysteroid variation during single molt cycle in generalized decapod larva. Shaded bars represent decapod molt phases (A-C: postmolt to intermolt; $\mathrm{D}_{0}$ : early premolt; $\mathrm{D}_{1}, \mathrm{D}_{2}$ : mid-premolt; $\mathrm{D}_{3-4}$ : late premolt). Short A-C period and initiation of ecdysteroid increase at end of the A-C period is apparent, as reported for larval decapods (Spindler \& Anger 1986, Anger \& Spindler 1987). Peak ecdysteroid level occurs in $\mathrm{D}_{2}$, as is typical in adult decapods; however, timing of peak varies among species and developmental stages (Skinner 1985) tive diapause of $C$. pacificus includes suppressed development at the fifth copepodid (CV) stage and descent to deep water for a period of several months (Osgood \& Checkley 1997a,b, Ohman et al. 1998). During diapause, calanoid copepodids remain at the postmolt jaw phase, the phase immediately following ecdysis, in contrast to actively developing CVs which develop through postmolt, intermolt, and premolt jaw phases (Miller et al. 1990). If the pattern of ecdysteroid variation during the molt cycle is similar in C. pacificus to that in other arthropods (Fig. 1), the ecdysteroid level should be low in postmolt individuals, and thus average ecdysteroid level should be lower in diapausing than in active C. pacificus CVs. The objectives of this study were to measure ecdysteroid variation through the molt cycle of C. pacificus CVs and to determine whether ecdysteroid levels of field-collected, diapausing and active C. pacificus CVs reflect their differences in molt-phase distribution.

\section{MATERIALS AND METHODS}

Most of the copepodids used for measurement of ecdysteroids during the molt cycle were grown from eggs spawned in the laboratory. Calanus pacificus copepodid and adult stages were collected about $3 \mathrm{~km}$ west of La Jolla, California ( $32^{\circ} 53^{\prime} \mathrm{N}, 117^{\circ} 17^{\prime} \mathrm{W}$ ) using a $333 \mu \mathrm{m}$ mesh net. Zooplankton were diluted with $0.2 \mu \mathrm{m}$ filtered seawater (FSW) and held at $16^{\circ} \mathrm{C}$ until C. pacificus could be sorted out, usually within $24 \mathrm{~h}$. Adult females sorted from samples were held in a $333 \mu \mathrm{m}$ mesh enclosure of approximately $20 \mathrm{l}$ suspended in $80 \mathrm{l}$ of aerated FSW at 10 to $12^{\circ} \mathrm{C}$. Females were fed a saturating mixed diet comprising Thalassiosira weissflogii, Rhodomonas salina and Gymnodinium sanguineum grown in semi-continuous culture at $18^{\circ} \mathrm{C}$. The mesh enclosure containing females was transferred to fresh FSW every 2 to $3 \mathrm{~d}$, and eggs and nauplii produced were concentrated by sieving. Eggs were grown to third- or fourth-stage copepodids (CIII and CIV) on a saturating mixed diet as described above.

Analyses of diapausing and active field-collected copepods were performed on copepods collected from the San Diego Trough, a 1200 m deep trough about $30 \mathrm{~km}$ west of San Diego, California $\left(32^{\circ} 38^{\prime} \mathrm{N}\right.$, $\left.117^{\circ} 32^{\prime} \mathrm{W}\right)$. Vertically-stratified samples were collected using a 10 net, $1 \mathrm{~m}^{2}$ MOCNESS (multiple opening and closing net and environmental sensing system) equipped with $333 \mu \mathrm{m}$ mesh. Day time and night time profiles were collected at 2 to $7 \mathrm{wk}$ intervals from April 2000 to March 2001. Zooplankton samples were quantitatively split using a Folsom plankton splitter, and half of each sample was preserved in $5 \%$ buffered Formalin and half was frozen in liquid nitrogen. Formalin- 
preserved Calanus pacificus were first enumerated to determine the vertical distribution of CVs, adults, and CIV stages. Dates of relatively high $\mathrm{CV}$ abundance in the upper $50 \mathrm{~m}$ were chosen for analysis (15 April, 13 May, 12 June, 19 July, 2 and 16 August, 28 November 2000; 19 January and 1 March 2001; all samples were from 0 to $50 \mathrm{~m}$; day and night samples were analyzed, except in July and March, when day samples only were analyzed). Deep strata chosen for analysis represent a range of dates and depths at which diapausing CVs were present (12 June: 300 to $350 \mathrm{~m}$; 19 July: 300 to $350 \mathrm{~m}$ and 900 to $1000 \mathrm{~m}$; 2 August: 350 to $400 \mathrm{~m}$ and 1000 to $1100 m_{i} 16$ August: 350 to $400 m_{i} 28$ November: 250 to $300 \mathrm{~m}$; night samples only were analyzed at all dates). Each of the selected surface and deep-water frozen samples was thawed on ice, and $70 \mathrm{CVs}$ were sorted from the zooplankton sample, blotted dry, and immediately transferred to a microcentrifuge tube containing $200 \mu \mathrm{l}$ of ice-cold $80 \%$ methanol.

To grow CVs to known times since molting, CIIIs and CIVs were sorted under a dissecting microscope and held in jars containing ca. 3.51 of unaerated FSW. I used 3 temperature treatments: 16,12 and $8^{\circ} \mathrm{C}$. The copepodids in the 12 and $8^{\circ} \mathrm{C}$ treatments were offspring of females collected on 6 November and 3 July 2001, respectively. Most copepodids used in the $16^{\circ} \mathrm{C}$ treatment were offspring of females collected on 18 June 2001; however, $28 \%$ were collected as copepodids on 18 June and 3 July 2001. Copepodids in each treatment were fed a saturating mixed diet, as detailed above, and exposed to a $12 \mathrm{~h} \mathrm{L:}: 12 \mathrm{~h}$ D photoperiod at a daytime irradiance of $0.5 \mu \mathrm{E} \mathrm{m}^{-2} \mathrm{~s}^{-1}$. Copepodids in all jars were checked and fed daily around midday, and the seawater was changed every third day. Individuals that had molted to the CV stage were removed to a new jar. To terminate the experiment, individual CVs were removed from the FSW, blotted dry, and transferred to microcentrifuge tubes containing $80 \mu \mathrm{l}$ of ice-cold $80 \%$ methanol.

Jaw-phase determinations were performed on a subset of CVs grown at $16^{\circ} \mathrm{C}$. Mandibles, which include the mandibular gnathobase (jaw), were dissected from whole copepods in a drop of $80 \%$ methanol. The mandibles were mounted on microscope slides in a 1:1 glycerol:water solution, and gross jaw phase (premolt or non-premolt) was determined using differential interference contrast (Nomarski) microscopy. Jaw phase was identified using morphological characteristics defined by Miller et al. (1990). Because the copepodids were fixed in methanol, the tissue was not well preserved, and postmolt and interphase jaws could not be differentiated. However, this preservation protocol was preferred because it allowed jaw phase and ecdysteroid analysis to be performed on the same individual $\mathrm{CV}$.

CVs were homogenized in microcentrifuge tubes using a Teflon or polypropylene pestle. In experiments measuring ecdysteroid variation throughout the molt cycle, CVs were homogenized individually; diapausing and active field-collected CVs were homogenized as pooled samples of 70 individuals. Tubes were chilled on ice during homogenization. Homogenates were centrifuged at $4^{\circ} \mathrm{C}(12500 \times g$ for $10 \mathrm{~min})$, and the supernatant was removed to a new microcentrifuge tube. The pellet was re-extracted with $100 \mu$ of ice-cold $80 \%$ methanol, re-centrifuged at $4{ }^{\circ} \mathrm{C}$, and the supernatants combined and dried under vacuum. The dried extracts were partitioned between chloroform $(200 \mu \mathrm{l})$ and water $(150 \mu \mathrm{l})$, and the chloroform phase was repartitioned with water $(100 \mu l)$. The water phases were combined and partitioned with $n$-hexane $(200 \mu l)$, and the hexane phase was repartitioned with water $(100 \mu \mathrm{l})$. The water phases were combined and dried under vacuum. Partitioning removed non-polar lipids, which would have interfered with the radioimmunoassay.

Ecdysteroids were measured by radioimmunoassay (RIA) as described by Chang \& O'Connor (1979). In this RIA, sample or standard ecdysteroids and tritiumlabeled ecdysone compete for binding sites on an antibody. After an incubation period, the antibody-antigen complex is precipitated and washed, and energy emission of the precipitate is measured by liquid scintillation counting. The mass of ecdysteroids in the sample is estimated by interpolation from a standard curve. The antibody used was ' $2 \mathrm{~A}$ ', which detects 25deoxy-ecdysone, 3-dehydroecdysone, ecdysone, and 20-hydroxyecdysone (Horn et al. 1976). The RIA was optimized for small sample sizes by using $6000 \mathrm{dpm}$ ${ }^{3} \mathrm{H}$-ecdysone and antiserum in a final concentration of $0.025 \%(\mathrm{v} / \mathrm{v})$. A set of 11 pairs of ecdysone standards from 5 to $4000 \mathrm{pg}$ was run with each set of samples. Pooled samples were analyzed in triplicate by RIA. Individual CVs were analyzed without replication because of their low ecdysteroid content.

Recovery rates were measured for unprocessed $50 \mathrm{pg}$ ecdysone standards, for $50 \mathrm{pg}$ ecdysone standards homogenized as for samples, and for $50 \mathrm{pg}$ ecdysone standards extracted as for samples. The recovery rate for unprocessed ecdysone standards was $83 \pm 27 \%$ ( $\mathrm{n}=$ $10)$, for homogenized standards $93 \pm 14 \%(\mathrm{n}=9)$, and for extracted standards $85 \pm 21 \%(n=15)$. There was no significant difference between recovery rates of the homogenized standards and of unprocessed standards (Student's $t$-test; $t_{0.05,17}=0.931, \mathrm{p}=0.36$ ) or between recovery rates of the extracted standards and of unprocessed standards $\left(t_{0.05,23}=0.157, \mathrm{p}=0.88\right)$.

\section{RESULTS}

Ecdysteroid content was low in laboratory-grown individual CVs sampled early in the molt cycle, 
increased to a peak part way during the molt cycle, and subsequently decreased at all 3 temperatures (Fig. 2). Individual copepod ecdysteroids were in some cases lower than the detection limit of the RIA (5 pg); most of these low values were measured in copepods early in the molting cycle. Because some ecdysteroid values were below the detection limit of the RIA, the central tendency was estimated using medians, and dispersion was estimated using quartiles and octiles (Zar 1996). In the $8^{\circ} \mathrm{C}$ treatment, only a small number of individuals was measured; therefore, several days were pooled in 2 cases ( 7 to 9 and 9 to $11 \mathrm{~d}$ ), and dispersion was estimated using quartiles only. Ecdysteroid variability was high throughout the molting cycle for all temperature treatments.

Ecdysteroid variation during the molt cycle can be interpreted relative to 3 different time scales: absolute time, developmental stage duration, and phases of the molt cycle. To account for the temperature-dependence of developmental stage duration, ecdysteroid variation during the molt cycle is shown relative to estimated CV stage duration (D in Fig. 2). Stage durations in the 16 and $12^{\circ} \mathrm{C}$ treatments were estimated as the time until initiation of molting to the adult stage (at which point the experiments were terminated). Estimated stage durations were 3 to $4 \mathrm{~d}$ and 5 to $6 \mathrm{~d}$ at 16 and $12^{\circ} \mathrm{C}$, respectively. On the first day that adults appeared, $48 \%(n=33)$ and $20 \%(n=80)$ of CVs molted to adults at $16^{\circ} \mathrm{C}$ and $12^{\circ} \mathrm{C}$, respectively. Thus, the timing of first appearance of adults was a good estimator of mean stage duration at $16^{\circ} \mathrm{C}$ but underestimated mean stage duration at $12^{\circ} \mathrm{C}$. Stage duration at $8^{\circ} \mathrm{C}$, estimated as the time when the percentage of $\mathrm{CVs}$ that had molted to adults was closest to $50 \%$, was 10 to $11 \mathrm{~d}(43 \%$ molted to adults; $\mathrm{n}=7$ ). Stageduration estimates at 16 and $12^{\circ} \mathrm{C}$ were shorter than those reported by Vidal (1980) for Calanus pacificus CVs (3 to $4 \mathrm{~d}$ vs $4.8 \mathrm{~d}$ at $15.5^{\circ} \mathrm{C}_{i} 5$ to $6 \mathrm{~d}$ vs $\left.6.25 \mathrm{~d}\right)$ but longer at $8^{\circ} \mathrm{C}$ (10 to $11 \mathrm{~d}$ vs $8.9 \mathrm{~d}$ ). Stage-duration estimates at $16^{\circ} \mathrm{C}$ were also shorter than those estimated by Landry (1983) for $C$. pacificus CVs grown at $15^{\circ} \mathrm{C}(4.7 \mathrm{~d})$. High mortality and high variability in stage durations observed in the $8^{\circ} \mathrm{C}$ treatment may reflect stress or a deficiency that resulted in longer stage duration. Observation of phytoplankton in the treatments suggested that such a deficiency could be due to reduced food availability caused by deterioration of cells in the low-temperature treatment.

The ecdysteroid level increased abruptly after approximately the first third of the molt period in both the 16 and $12^{\circ} \mathrm{C}$ treatments (Fig. 2). At $16^{\circ} \mathrm{C}$, ecdysteroids decreased gradually during the last two-thirds of the molt period. At $12{ }^{\circ} \mathrm{C}$, the peak was broader and centered at about one-half of the molt period and was subsequently followed by a decline. In the $8^{\circ} \mathrm{C}$ treatment, ecdysteroids increased more gradually to a broad peak
Fig. 2. Calanus pacificus. Ecdysteroid content in individual fifth copepodid (CV) stages during molt cycle. CVs were grown at 16,12 or $8^{\circ} \mathrm{C}$. Curves connect median values, gray and white boxes represent quartiles and octiles, respectively, whiskers represent range; dashed line: detection limit at $5 \mathrm{pg}$ ecdysone-equivalents; values in parentheses: number of individual CVs analyzed whose ecdysteroid content was below detection limit; total sample size is shown above whiskers. Abscissa scales normalized to estimated CV stage duration (D). Range and data only are plotted for Days 3 to 4 and 4 to 5 in $16^{\circ} \mathrm{C}$ treatment because of small sample sizes. Data for several days are pooled in the $8^{\circ} \mathrm{C}$ treatment (Days 7 to 9 and 9 to 11) because of small sample sizes, and combined ecdysteroid data are plotted at weightedmean time since onset of $\mathrm{CV}$ 
later in the molt period than in the 16 and $12^{\circ} \mathrm{C}$ treatments. In absolute time, ecdysteroid increased and peaked earliest at $16^{\circ} \mathrm{C}$ and latest at $8^{\circ} \mathrm{C}$. Peak median ecdysteroid level was highest at $16^{\circ} \mathrm{C}$ and lowest at $8^{\circ} \mathrm{C}$.

Jaw phases were analyzed in a subset of CV stages reared at $16^{\circ} \mathrm{C}$. The non-premolt jaw phase was observed during the first day (Days 0 to 1 ) after molting to CV. Premolt jaw phase first appeared (in $35 \%$ of the copepodids) on Days 1 to 2, and this was the dominant phase 2 to 3 d after molting (90\% of copepodids), occurring in $100 \%$ of copepodids Days 3 to 5 after molting (Fig. 3). Ecdysteroid content was higher in premolt than in non-premolt individuals (Mann-Whitney $U$-test: $U_{0.05(1), 23,31}=478.5, \mathrm{p}=0.017$ ). Comparison of ecdysteroid content and jaw phase between individuals suggests that ecdysteroid increases at the end of intermolt to a peak at the beginning of premolt. Median ecdysteroid content of non-premolt individuals 1 to $2 \mathrm{~d}$ after molting was significantly higher than that of non-premolt individuals 0 to $1 \mathrm{~d}$ after molting (Table 1). The median ecdysteroid content of premolt individuals was also significantly higher 1 to $2 \mathrm{~d}$ after molting than 2 to $5 \mathrm{~d}$ after molting (Table 1 ).

RIA was used to characterize the ecdysteroid level of field-sampled Calanus pacificus CVs. Shallow and deep CVs were spatially well-separated, and deep CVs were presumed to be diapausing based on the dominance of CVs among C. pacificus below $200 \mathrm{~m}$ and the high percentage of deep CVs with postmolt jaws (>90\% from June to November). In contrast, all developmental stages and CV jaw phases were well represented above $100 \mathrm{~m}$ (author's unpubl. data). Average ecdysteroid content was lower in deep dia-

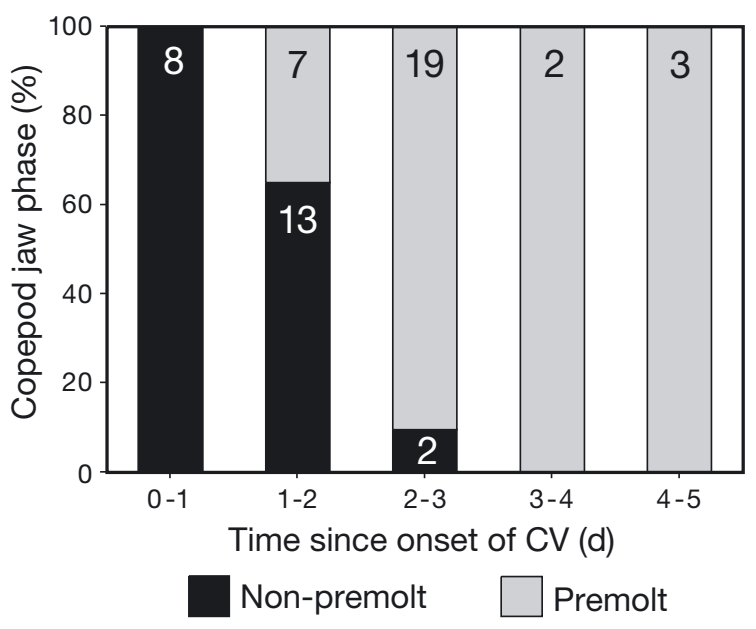

Fig. 3. Calanus pacificus. Jaw proportions of fifth copepodid (CV) stages grown at $16^{\circ} \mathrm{C}$ under controlled laboratory conditions. Jaws were dissected from CVs represented in top panel of Fig. 2. Sample sizes of non-premolt and premolt jaws are shown on respective bars
Table 1. Calanus pacificus. Comparison of ecdysteroid content (pg ecdysone-equivalents ind.$^{-1}$ ) in fifth-stage copepodids (CVs) as a function of jaw phase (non-premolt and premolt) and time (d) since molting. CVs grown in the laboratory at $16^{\circ} \mathrm{C}$. Central tendency was estimated from the median. A Mann-Whitney $U$-test tested for differences between medians

\begin{tabular}{|lc}
\hline $\begin{array}{l}\text { Phase } \\
\text { Time }\end{array}$ & Ecdysteroid content \\
\hline Non-premolt & \\
$0-1$ d since molt & 9.6 \\
1-2 d since molt & 34.6 \\
Mann-Whitney $U_{8,13}$ & 103 \\
p & $<0.001$ \\
Premolt & \\
$1-2$ d since molt & 64.7 \\
$2-5$ d since molt & 29.7 \\
Mann-Whitney $U_{7,24}$ & 148 \\
p & $<0.002$ \\
\hline
\end{tabular}

pausing CVs $\left(1.7 \pm 0.6 \mathrm{pg}\right.$ ecdysone-equivalents ind.$^{-1}$; mean $\left.\pm \mathrm{SD}_{i} \mathrm{n}=7\right)$ than in surface active CVs $(6.2 \pm$ $4.0 \mathrm{pg}$ ecdysone-equiv. ind. ${ }^{-1} ; \mathrm{n}=16$ ) (Student's $t$-test, $\left.t_{0.05,21}=-2.886, \mathrm{p}=0.009\right)$.

\section{DISCUSSION}

The overall pattern of ecdysteroid variation during the molt cycle of Calanus pacificus CVs, in which levels were low after molting, increased to a peak, and decreased before ecdysis, was similar to the cyclic ecdysteroid pattern in larval, juvenile and adult decapods (Chang et al. 2001). This pattern was evident despite high ecdysteroid variability. This variability may result from asynchronous development among copepods at a given temperature or from brief, transient ecdysteroid fluctuations in individuals, such as described for lobsters by Snyder \& Chang (1991b). Analytic error in the RIA, exacerbated by an unavoidable lack of replication in individual $\mathrm{CV}$ analyses, also contributed to the observed variability. Ecdysteroids peaked earlier, relative to developmental stage duration, in C. pacificus CVs at 16 and $12^{\circ} \mathrm{C}$ than in larval lobsters or crabs, and much earlier than in adult decapods, which have a very long intermolt (C) phase (Chang \& Bruce 1981, Spindler \& Anger 1986). The short intermolt period of copepods is typical of animals that molt rapidly and continuously rather than at long intervals (e.g. seasonally) (Knowles \& Carlisle 1956).

The coincidence of the peak median ecdysteroid level and the first appearance of premolt jaws on Days 1 to 2 in the $16^{\circ} \mathrm{C}$ treatment (Table 1) suggests an ecdysteroid peak early in premolt, as in decapod larvae (Anger \& Dawirs 1981, Spindler \& Anger 1986). 
Although the copepod jaw phases defined by Miller et al. (1990) have not been related to decapod molt phases, both the premolt jaw phase in copepods and the premolt phase in decapods are initiated when apolysis (separation of the cuticle from the epidermis) begins in body parts that undergo the most marked changes (Miller et al. 1990, Anger 2001). Therefore, premolt phases as defined for copepods and decapods probably delimit very similar developmental periods. Here, I assume that ecdysteroids increase to a peak in early premolt at 12 and $8^{\circ} \mathrm{C}$, as they do at $16^{\circ} \mathrm{C}$.

The relationship between molt-phase duration and temperature is equivocal. The similarity in ecdysteroid peak timing at 16 and $12^{\circ} \mathrm{C}$ is consistent with change in premolt duration that is proportional to a temperaturedependent change in stage duration. However, differences in temporal resolution in the 2 treatments prevent detection of small differences in relative molt phase duration that might contradict this hypothesis. The delayed ecdysteroid peak in the $8^{\circ} \mathrm{C}$ treatment is consistent with a point-of-reserve saturation (PRS) response. The PRS, most commonly associated with food-limitation and believed to correspond to the $\mathrm{D}_{0}$ premolt stage in decapod larvae (Fig. 1), is the point in the molt cycle at which an individual has accumulated enough energy reserves to complete development through ecdysis without further feeding (Anger \& Dawirs 1981, Anger \& Spindler 1987). Under foodlimiting conditions, pre-PRS individuals would slow or stop development while post-PRS individuals would complete the molt cycle without delay, resulting in increased postmolt and intermolt durations but constant premolt duration. Although the food concentration at $8^{\circ} \mathrm{C}$ was intended to be saturating, the long developmental stage duration, asynchrony of development, and high mortality in this treatment indicate food limitation or other stress. Therefore, the delayed ecdysteroid peak at $8^{\circ} \mathrm{C}$ may be a PRS response to food-limitation. Alternatively, it may be a PRS-type response to temperature near the lower limit physiologically tolerable by Calanus pacificus (Anger 2001). Non-linear changes in the proportion of a developmental stage spent in premolt, in which premolt duration deviates from a constant proportion of stage duration only at extreme temperatures, have also been inferred for Daphnia magna (Espie \& Roff 1995). Further work will be required to clarify the relationship between molt-phase duration and temperature.

The low ecdysteroid content observed in diapausing Calanus pacificus CVs compared to surface active CVs is consistent with the differing jaw-phase distributions in these 2 groups. The ecdysteroid content of pooled, deep, diapausing CVs, $1.7 \mathrm{pg}$ ecdysone-equiv. ind. ${ }^{-1}$, was below the detection limit for individual CVs, consistent with the ecdysteroid values of individuals just after molting (Fig. 2), which were largely below the 5 pg detection limit. A bootstrap simulation was performed to calculate the average ecdysteroid level expected if CVs in the field were undergoing continuous development as in the laboratory. Bootstrap samples $(n=5000)$ were generated from a population in which one-third of individuals were postmolt or intermolt and two-thirds were premolt, similar to the laboratory-grown CVs. Individual ecdysteroid levels were drawn from 1 of 2 normal distributions: postmolt-intermolt, $3.0 \pm 1.5$ pg ecdysone-equiv. ind. ${ }^{-1}$ (mean $\pm \mathrm{SD}$ ); and premolt, $28 \pm 15 \mathrm{pg}$ ecdysone-equiv. ind. ${ }^{-1}$. Premolt mean and SD were estimated from ecdysteroid levels of Days 2 to 5 individuals at $12^{\circ} \mathrm{C}$. The postmoltintermolt mean was estimated as the average of the ecdysteroid level of diapausing field-collected CVs and the RIA detection limit; the SD was estimated as half of the mean. The ecdysteroid content of surface CVs (6.2 pg ecdysone-equiv. ind. ${ }^{-1}$ ) was lower than the expected ecdysteroid level calculated in the simulation (21 pg ecdysone-equiv. ind. ${ }^{-1}$ ) and fell well outside the $95 \%$ bootstrap confidence intervals of 17 and $25 \mathrm{pg}$ ecdysone-equiv. ind. ${ }^{-1}$. This difference probably reflects a greater proportion of postmolt and intermolt individuals in field-collected samples than predicted by development in the laboratory (author's unpubl. data). Both food-limitation and preparation for diapause could cause a shift toward postmolt jaw phases. Measurements that could distinguish these 2 conditions, such as lipid analysis or carbon and nitrogen condition factors (weight $\mathrm{C}$ or $\mathrm{N}$ length ${ }^{-3}$ ), were not performed. Differences in preparation of field-collected and laboratory-grown CVs (i.e. sorting thawed vs fresh CVs) could also bias field measurements toward lower ecdysteroid levels.

The pattern of ecdysteroid variation during the molt cycle identified here for Calanus pacificus CVs provides evidence that ecdysteroids control molting in copepods as in other arthropods. In addition, contrasting ecdysteroid levels in diapausing and active CVs suggest that hormonal analysis can provide insights into the life-history status of field-collected copepods. Diapause is a key component of the life cycle of Calanus species; however, the mechanisms of diapause induction and termination are not understood and are under active debate (Hind et al. 2000). Ecdysteroid analysis may provide a valuable tool for identifying environmental cues associated with diapause induction, thus facilitating formulation of diapause induction models that can assess the impacts of diapause on Calanus spp. population dynamics and predict the effects of environmental change on diapause response in this extremely abundant genus. Ecdysteroids are low during diapause, and therefore they can, at most, indirectly control diapause. Further exploration of cope- 
pod hormones in nature will be necessary to identify hormones that directly control diapause, perhaps by suppressing ecdysteroid secretion or by stimulating a hormone analogous to the molt-inhibiting hormone $(\mathrm{MIH})$ in decapods. Neurosecretory cells in the head region, which have been observed to change during diapause in 2 copepod genera, may be implicated in diapause control (Carlisle \& Pitman 1961, Watson \& Smallman 1971). Insights and immunohistochemical tools from crustacean and insect endocrinology may greatly accelerate progress in understanding copepod endocrinology and in applying such understanding to ecological questions.

Acknowledgements. Antiserum was generously supplied by W. E. Bollenbacher, University of North Carolina, Chapel Hill, and distributed by E. S. Chang, Bodega Marine Laboratory. I am grateful to E. S. Chang for sharing his expertise in ecdysteroid analysis and to R. S. Burton for providing laboratory facilities for the RIAs. This manuscript was improved by helpful comments from R. S. Burton, E. S. Chang, D. M. Checkley, C. DiBacco, M. D. Ohman, C. B. Miller and 3 anonymous reviewers. This research was supported by the Office of Naval Research through Contract N00014-11-10172 to D. M. Checkley. C.L.J. was also supported by a National Defense Science and Engineering Graduate Fellowship and by a scholarship from the Achievement Rewards for College Scientists Foundation, San Diego Chapter.

\section{LITERATURE CITED}

Anger K (2001) The biology of decapod crustacean larvae. AA Balkema, Rotterdam

Anger K, Dawirs RR (1981) Influence of starvation on the larval development of Hyas araneus (Decapoda, Majidae). Helgol Meeresunters 34:287-311

Anger K, Spindler KD (1987) Energetics, moult cycle and ecdysteroid titers in spider crab (Hyas araneus) larvae starved after the $\mathrm{D}_{0}$ threshold. Mar Biol 94:367-376

Carlisle DB (1965) The effects of crustacean and locust ecdysons on moulting and proecdysis in juvenile shore crabs, Carcinus maenas. Gen Comp Endocrinol 5:366-372

Carlisle DB, Pitman WJ (1961) Diapause, neurosecretion, and hormones in Copepoda. Nature 190:827-828

Chang ES (1995) Physiological and biochemical changes during the molt cycle in decapod crustaceans: an overview. J Exp Mar Biol Ecol 193:1-14

Chang ES, Bruce MJ (1981) Ecdysteroid titers of larval lobsters. Comp Biochem Physiol A 70:239-241

Chang ES, O'Connor JD (1979) Arthropod molting hormones. In: Jaffe BM, Behrman HR (eds) Methods of radioimmunoassay. Academic Press, New York, p 797-814

Chang ES, Chang SA, Mulder EP (2001) Hormones in the lives of crustaceans: an overview. Am Zool 41:1090-1097

Charmantier G, Charmantier-Daures M, Van Herp F (1997) Hormonal regulation of growth and reproduction in crustaceans. In: Fingerman M, Nagabhushanam R, Thompson MF (eds) Endocrinology and reproduction, Vol 1. Science Publishers, Enfield, NH, p 109-201

Crain JA, Miller CB (2001) Effects of starvation on intermolt development in Calanus finmarchicus copepodites: a comparison between theoretical models and field studies. Deep-Sea Res II Top Stud Oceanogr 48:551-566

Editorial responsibility: Michael Landry (Contributing Editor), Honolulu, Hawaii, USA
Drach P (1939) Mue et cycle d'intermue chez les crustacés décapodes. Annu Inst Oceanogr 19:103-391

Espie PJ, Roff JC (1995) A biochemical index of duration of the molt cycle for planktonic Crustacea based on the chitin-degrading enzyme, chitobiase. Limnol Oceanogr 40:1028-1034

Hind A, Gurney WSC, Heath M, Bryant AD (2000) Overwintering strategies in Calanus finmarchicus. Mar Ecol Prog Ser 193:95-107

Horn DHS, Wilkie JS, Sage BA, O'Connor JD (1976) A high affinity antiserum specific for the ecdysone nucleus. J Insect Physiol 22:901-905

Knowles FGW, Carlisle DB (1956) Endocrine control in the Crustacea. Biol Rev Camb Philos Soc 31:396-473

Landry MR (1983) The development of marine calanoid copepods with comment on the isochronal rule. Limnol Oceanogr 28:614-624

Miller CB, Terazaki M (1989) The life histories of Neocalanus flemingeri and Neocalanus plumchrus in the Sea of Japan. Bull Plankton Soc Jpn 36:27-42

Miller CB, Nelson DM, Weiss C, Soeldner AH (1990) Morphogenesis of opal teeth in calanoid copepods. Mar Biol 106: 91-102

Miller CB, Cowles TJ, Wiebe PH, Copley NJ, Grigg H (1991) Phenology in Calanus finmarchicus: hypotheses about control mechanisms. Mar Ecol Prog Ser 72:79-91

Nijhout HF (1994) Insect hormones. Princeton University Press, Princeton, NJ

Ohman MD, Drits AV, Clarke ME, Plourde S (1998) Differential dormancy of co-occurring copepods. Deep-Sea Res Part II Top Stud Oceanogr V45:1709-1740

Osgood KE, Checkley DM (1997a) Observations of a deep aggregation of Calanus pacificus in the Santa Barbara Basin. Limnol Oceanogr 42:997-1001

Osgood KE, Checkley DM (1997b) Seasonal variations in a deep aggregation of Calanus pacificus in the Santa Barbara Basin. Mar Ecol Prog Ser 148:59-69

Skinner DM (1985) Molting and regeneration. In: Bliss DE, Mantel LH (eds) Integument, pigments, and hormonal processes, Vol 9. Academic Press, Orlando, p 44-128

Snyder MJ, Chang ES (1991a) Ecdysteroids in relation to the molt cycle of the American lobster, Homarus americanus: II. Excretion of metabolites. Gen Comp Endocrinol 83: $118-131$

Snyder MJ, Chang ES (1991b) Ecdysteroids in relation to the molt cycle of the American lobster, Homarus americanus: I. Hemolymph titers and metabolites. Gen Comp Endocrinol 81:133-145

Spindler KD, Anger K (1986) Ecdysteroid levels during the larval development of the spider crab Hyas araneus. Gen Comp Endocrinol 64:122-128

Spindler KD, Przibilla S, Spindler-Barth M (2001) Moulting hormones of arthropods: molecular mechanisms. Zoology 103:189-201

Steel CGH, Vafopolou X (1989) Ecdysteroid titer profiles during growth and development of arthropods. In: Koolman J (ed) Ecdysone: from chemistry to mode of action. Georg Thieme-Verlag, Stuttgart, p 482

Vidal J (1980) Physioecology of zooplankton. II. Effects of phytoplankton concentration, temperature, and body size on the development and molting rates of Calanus pacificus and Pseudocalanus sp. Mar Biol 56:135-146

Watson NHF, Smallman BN (1971) The physiology of diapause in Diacyclops navus Herrick (Crustacea, Copepoda). Can J Zool 49:1449-1454

Zar JH (1996) Biostatistical analysis, 3rd edn. Prentice-Hall, Upper Saddle River, NJ

Submitted: September 2, 2002; Accepted: March 23, 2003

Proofs received from author(s): July 14, 2003 